\title{
Role of Visual Dysfunction in Postural Control in Children with Cerebral Palsy
}

\author{
G. Porro, D. van der Linden, O. van Nieuwenhuizen ${ }^{1}$ and D. Wittebol-Post \\ Departments of Ophthalmology and ${ }^{1}$ Child-Neurology, University Medical Center, Utrecht, the Netherlands
}

\begin{abstract}
Introduction: Deficient postural control is one of the key problems in cerebral palsy (CP). Little, however, is known about the specific nature of postural problems of children with $\mathrm{CP}$, nor of the relation between abnormal posture and dysfunction of the visual system. Aim of the study: To provide additional information on the association of abnormalities in postural control and visual dysfunction of the anterior or posterior part of the visual system. Methods: Data resulting from ophthalmologic, orthoptic, neurological, neuro-radiological, and ethological investigations of more than 313 neurologically impaired children were retrospectively analyzed. Results: Abnormal postural control related to ocular and ocular motor disorders consisted of anomalous head control and subsequent abnormal head posture and torticollis. The abnormal postural control related to retrochiasmatical damage of the visual system consisted of a torticollis combined with adjustment of the upper part of the body, as if at the same time adapting to a combination of defects and optimizing residual visual functions. Conclusion: Visual dysfunctions play. a distinct role in the postural control of children with CP.
\end{abstract}

Reprint requests to: $\mathrm{G}$. Porro $\mathrm{MD}, \mathrm{PhD}$, Department of Ophthalmology, University Medical Center Utrecht, Neuroophthalmological Center, AZU, Heidelberglaan 100, 3584 CX Utrecht, the Netherlands; e-mail: G.Porro@hconet.nl

\section{INTRODUCTION}

The central nervous system (CNS) initiates and coordinates movements and regulates sensory information from visual, somatosensory, and vestibular systems to maintain balance and postural orientation during standing, walking, running, and skilled use of the hands. Vision plays an important role in controlling the position of the head in space (Buchanan, 1999). On the other hand, head stability is important for vision, as it fosters gaze stability and therefore image stability on the retina, facilitating the processing of visual information (Dan, 2000). Deficient postural control is one of the key problems in cerebral palsy (CP) (Aicardi , 1998; Van der Heide, 2004), a clinically used umbrella term indicating a heterogeneous group of patients suffering from a disorder of movement and posture due to a non-progressive lesion of the developing brain. Cerebral palsy can be caused by pre-, peri-, or post-natal lesions. An important cause of $\mathrm{CP}$ is perinatal hypoxic-ischemic damage in premature infants (Dan, 2000).

Cerebral palsy is often accompanied by a dysfunction of the visual system (Van Nieuwenhuizen, 1987) consisting of an anterior part-both eyes and the optic nerves up to the optic chiasmand a posterior part-the optic tracts, the lateral geniculate nuclei, the optic radiations and the occipital cortex. About $48 \%$ of children with CP are at risk for dysfunction of the visual system as opposed to $4 \%$ to $5 \%$ of the child population in general (Schenk, 1994), and the incidence is increasing dramatically in the western world (Rudanko, 2003; Steinkuller, 1999). 
Little is known about the specific nature of postural problems in children with CP (HaddersAlgra, 1999) nor of the relation between abnormal posture and dysfunction of the visual system (Brodsky, 2002). Therefore, we sought to document associations between abnormalities of posture and dysfunction in the visual system in children with $\mathrm{CP}$.

\section{PATIENTS AND METHODS}

Data resulting from ophthalmologic, orthoptic, neurological, and neuro-radiological examinations of 313 neurologically impaired children seen in the Departments of Child Neurology and Ophthalmology of the University Medical Center of Utrecht during the last 10 years were retrospectively analyzed. The children were aged from 8 months to 16 years (range: $6 \mathrm{y}$; SD: $3 \mathrm{y}, 3 \mathrm{mo}$ ). Next to routine ophthalmologic and orthoptic examination, children with a steady fixation under-went a simple behavioral visual field test (BEFIE test). The BEFIE test, acronym of Behavioral Visual Field Screening test, consists of a modified arc perimeter to assess the peripheral visual field of young and/or neurologically impaired children in a clinical setting (Porro, 1998). Children who were not able to fixate properly underwent an ethological investigation (Porro, 1998). Ethology is a scientific study of animal (and human) behavior that focuses on forming questions, namely the proximate and the ultimate causation of behaviors and on the evolution of behaviors.

\section{RESULTS}

Neurological examination confirmed the diagnosis of CP (spastic, dyskinetic, or ataxic) in most of the children. Neuroradiologically, in 139 of the 313 children (44\%) lesions of the posterior visual pathways and/or occipital cortex were found (Table 1), indicating cerebral visual impairment (CVI) (Van Nieuwenhuizen, 1983; M.O'Keefe, 1998).

Analysis of ophthalmologic and orthoptic examinations showed ocular-, adnexal-, and ocularmotor disturbances that caused abnormal posture of the head in $26(15 \%)$ of the 174 children with dysfunction of the anterior part of the visual system (Table 2). This so-called torticollis consisted of face turn and/or head tilt, whether or not accompanied by chin depression or elevation and head oscillation. In the 139 children (44\%) with dysfunction of the posterior part of the visual system, causing CVI, we found a combination of postural strategies, viz. torticollis with abnormal posture of the upper part of the body, such as withdrawal, which was mainly associated with the torticollis (Table 3). In these 139 children, visual field defects were often present, such as hemianopia $(31 \%)$, tubular vision $(20 \%)$, quadrantanopia (11\%), or temporal restriction (7\%). Of the 313 neurologically impaired children in our study, 83 (27\%) suffered from spastic hemiplegia. In 43 of the 83 children (54\%), an homonymous hemianopia was found. Moreover, in 10 of the 43 children with spastic hemiplegia and homonymous hemianopia, a torticollis toward the homonymous visual field defect was found.

In children with unsteady fixation who seemed to be blind, ethological analysis showed a number of postural changes and neurobehavioral adaptions, classified as direct and indirect signs of visual perception (Porro, 1998). We considered looking away while reaching the stimulus, looking past the stimulus ("overlooking"), or turning away the head/eyes away together with withdrawal of the upper body in response to stimulus presentation ("avoiding") direct signs of visual perception; change of posture and stereotypic behaviors indicating excitement or anxiety caused by the stimulus indirect signs of visual perception. 
TABLE 1

Main causes of CVI in this study

- Vascular lesions

- Hemorrhagic lesions

- Ischemic lesions

- Periventricular leukomalacia (PVL)

- Infarct in the territory of the arteria cerebri media or posterior

- Hydrocephalus

- Meningo-encephalitis

- Intrauterine infections (Cytomegalovirus, Toxoplasmosis)

TABLE 2

Dysfunctions of the anterior part of the visual system leading to abnormal postural control

a) Ocular dysfunctions

- Ptosis

- Refractive errors (i.e uncorrected astigmatism)

- Cornea or lens opacities (i.e. cataract)

- Diseases of the retina (i.e. retinal coloboma's, retinitis pigmentosa)

- Diseases of the optic nerve (i.e. optic nerve hypoplasia)

b) Oculomotor dysfunctions

- Dyskinetic strabismus (i.e. Alphabetical disturbances of ocular motility, viz. A- and V-patterns, Dissociated Vertical Deviation)

- Ocular motor abnormalities (i.e. III, IV and VI nerve palsy)

- Nystagmus

- Spasmus Nutans

- Ocular motor apraxia 
TABLE 3

Relationship of abnormalities of posture and dysfunction in the visual system in 313 children with cerebral palsy

\begin{tabular}{cl}
\hline \multicolumn{1}{c}{ Type of Fixation } & \multicolumn{1}{c}{ Postural Abnormalities } \\
\hline Steady $(\mathrm{N}=270)$ & \\
Without CVI $(\mathrm{N}=172)$ & Torticollis $(\mathrm{N}=26)$ \\
With CVI $(\mathrm{N}=98)$ & Torticollis $(\mathrm{N}=12)$ \\
& Withdrawal of upper part of body $(\mathrm{N}=5)$ \\
Unsteady $(\mathrm{N}=43)$ & \\
Without $\mathrm{CVI}(\mathrm{N}=2)$ & \\
& \\
With CVI $(\mathrm{N}=41$ & Turning away of head $(\mathrm{N}=7)$ \\
& Withdrawal of upper body $(\mathrm{N}=4)$ \\
& Looking away, overlooking $(\mathrm{N}=6)$ \\
& Head rocking, flapping $(\mathrm{N}=2)$ \\
\hline
\end{tabular}

\section{DISCUSSION}

In our group of brain-damaged children, the most frequently found abnormal posture was abnormal posture of the head (torticollis) found in children with abnormalities of both anterior and posterior parts of the visual system. In ocular, ocular motor, visual field, and adnexal (viz. ptosis) abnormalities, an abnormal head posture is usually adopted to obtain better visual acuity or to obtain or maintain a field of binocular single vision and place it centrally. Torticollis can consist of a face turn, a head tilt, chin elevation, or chin depression (Ansons, 2001).

Abnormal postural control that was related to abnormalities of the posterior part of the visual system and/or occipital cortex often consisted of a combination of different postural strategies, such as torticollis combined with adjustment of the upper part of the body.

This torticollis appeared to be more complex. As if at the same time, adapting to a combination of defects and to optimize residual visual functions, including defective visual fields, abnormalities of ocular motility, as well as motor handicaps. Conversely, vision and visual field play an important role in postural control (Bardy, 1999; Turano, 1996), and visually impaired children have a greater instability than do sighted children (Portfors-Yeomans, 1995).

Our findings confirm the data of Prayson and Hannahoe (2004) that more than $50 \%$ of children affected by spastic hemiplegia suffer from homonymous hemianopia. In 10 hemiplegic children with homonymous hemianopia, a torticollis toward the homonymous visual field defect was found, 
probably to centralize the visual field (compensatory torticollis).

We speculate that the visual and motor systems in children with CP interact in search of the best postural control for the specific visual dysfunction. According to the "theory of latent heliotropism" of Brodsky, the torticollis that accompanies congenital homonymous hemianopia can attest to the primitive role of vision in establishing baseline muscle tone. In fact, humans born with homonymous hemianopia maintain a curious head turn away from the side of the seeing visual field (Brodsky, 2002).

Children frequently activate neck extensors during reaching. According to several authors (Van der Heide, 2004; Hadders-Algra, 1999), however, children with spastic hemiplegia activate neck extensors significantly more often and earlier ("early neck extensor recruitment") than do healthy children or children with a bilateral form of spastic CP. Moreover, children with spastic hemiplegia and a severe brain lesion (i.e a PVL grade III or a hemorrhage grade IV) have a significantly shorter "neck extensor onset latency" than do children with a milder or no brain lesion. Considering the high percentage of visual field defects $(54 \%)$ in children affected by spastic hemiplegia found in this study, we speculate that the early and frequent activation of neck extensors in hemiplegic children with severe brain lesions is at least partially due to a compensatory torticollis toward the homonymous visual field defect in order to centralize the functional visual field.

We found both direct and indirect signs of visual perception in children with CVI and unsteady fixation, who seemed to be blind (Porro, 1998), as did Fazzi (Fazzi, 1999). Stereotyped behaviors, such as "head rocking" and "flapping" and neurobehavioral adaptations, such as "looking past" or "looking away while reaching the stimulus" in children with unsteady fixation, can also play an important role in the long-term postural control of children with $\mathrm{CP}$.
In recognizing that the visual system exerts influence on the tonus of the body musculature via the CNS, Meyer and Bullock (1977) proposed that the eyes function not merely as sensory organs but also as components of a multi-modally driven tonus pool that calibrates baseline muscle tone. According to Brodsky (2002), redirecting our attention to the posture of patients with congenital visual disorders should be helpful in deducing and quantifying the role of vision in regulating human muscle tone (Brodsky, 2002).

In conclusion, visual dysfunctions seem to play a distinct role in the postural control of children with CP. Further studies on the relations between vision and postural control are necessary to provide more clues to understanding those fascinating but complex and challenging compensatory mechanisms, in order to develop therapeutic interventions.

\section{ACKNOWLEDGMENT}

The authors thank the Stichting ODAS for financial support.

\section{REFERENCES}

Aicardi J, Bax M. 1998. Diseases of the nervous system in childhood. Cambridge, UK: Mac Keith Press.

Ansons AM, Davis H. 2001. Diagnosis and management of ocular motility disorders, $3^{\text {rd }}$ ed. Oxford, UK: Blackwell Science Limited; 11.

Bardy BG, Warren Wh Jr, Kay BA. 1999. The role of central and peripheral vision in postural control during walking. Percept Psychophys 61: 1356-1368.

Brodsky MC. 2002. Latent heliotropism. Br J Opththalmol 86: 1327-1328.

Buchanan JJ, Horak FB. 1999. Emergence of postural patterns as a function of vision and translation frequency. J Neurophysiol 81: 2325-2339.

Dan B, Bouillot E, Bengoextea A, Noel P, Kahn A, Cheron G. 2000. Head stability during whole 
body movements in spastic diplegia. Brain Dev 22: 99-101.

Fazzi E, Lanners J, Danova S, Ferrari-Ginevra O, Cheza C, Luparia A. et al. Stereotyped behaviors in blind children. Brain Dev 1999; $21: 522-528$.

Hadders-Algra $M$, van der Fits IB, Stremmelar EF, Touwen BC. 1999; Development of postural adjustments during reaching in infants with $\mathrm{CP}$. Dev Med Child Neurol 41, 766-776.

Meyer DL, Bullock TH. 1977. The hypothesis of sense-organ dependent tonus mechanism: history of a concept. Ann NY Acad Sci 290: 173.

O'Keefe M. 1998. Is my child blind? In: Rosen ES, Eustace P, Thompson HS, Cumming WJ, eds, Neuro-ophthalmology. London, UK: Mosby.

Porro G, Dekker EM, van Nieuwenhuizen $O$, Wittebol-Post D, Schilder MB, Schenk-Rootlieb AJ, et al. 1998. Visual behaviors of neurologically impaired children with cerebral visual impairment: an ethological study. Br J Ophthalmol 82: 1231-1235.

Porro G, Hofmann J, Wittebol-Post D, van Nieuwenhuizen O, van der Schouw YT, Schilder MBH et al. 1998. A new behavioral visual field test for clinical use in pediatric neuro-ophthalmology. Neuro-ophthalmology 19: 205-214.

Portfors-Yeomans CV, Riach CL. 1995. Frequency characteristics of postural control of children with and wiothout visual impairment. Dev Med Child Neurol 37: 456-456.

Prayson RA, Hannahoe BM. 2004. Clinicopathological findings in patients with infantile hemiparesis and epilepsy. Hum Pathol 35: 734-738.

Rudanko SL, Fellman V, Laatikainen L. 2003. Visual impairment in children born prematurely from 1972 through 1989. Opthalmology 110: 1639-1645.

Schenk Rootlieb AJF. 1994. Cerebral Palsy and Vision. Utrecht, the Netherlands: Offset Edition.

Steinkuller PG, Du L, Gilbert C, Foster A, Collins ML, Coats DK. 1999. Childhood blindness. J AAPOS 3: 26-32.

Turano KA, Dagnelie G, Herdman SJ. 1996. Visual stabilization of posture in persons with central visual field loss. Invest. Ophthalmol Vis Sci 37: 1483-1491.

Van der Heide JC, Begeer C, Fock JM, Otten B, Stremmelaar E, van Eykern LA, et al. 2004. Postural control during reaching in preterm children with cerebral palsy. Dev Med Child Neurol 46, 253-266.

Van Nieuwenhuizen $O$, Van Waes R, Willemse J. 1983. Computerised tomographic abnormalities in children with cerebral visual disturbance. Lancet, 1: 868-869.

Van Nieuwenhuizen O. 1987. Cerebral visual disturbance in infantile encephalopathy. Dordrecht, the Netherlands: Martinus Nijhoff-W. Junk Publ. 

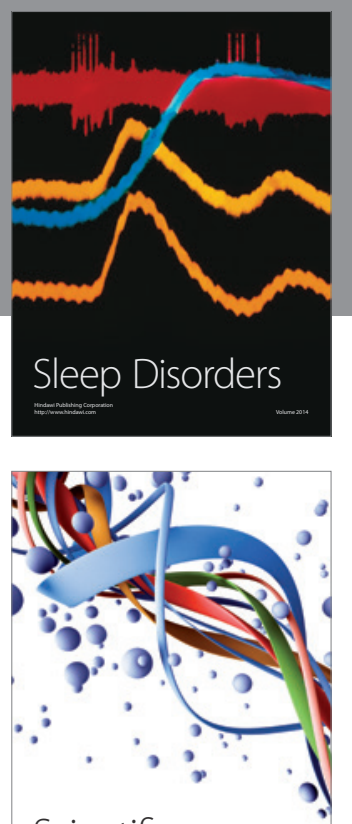

Scientifica
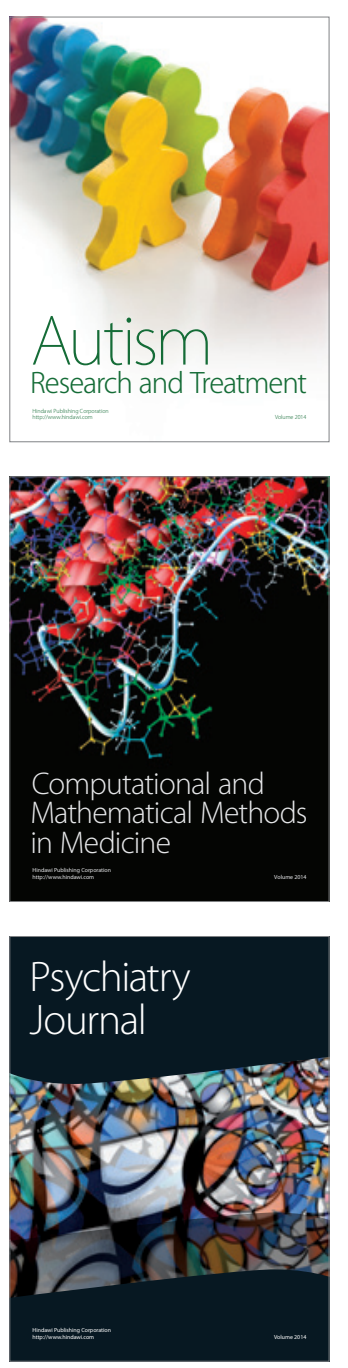
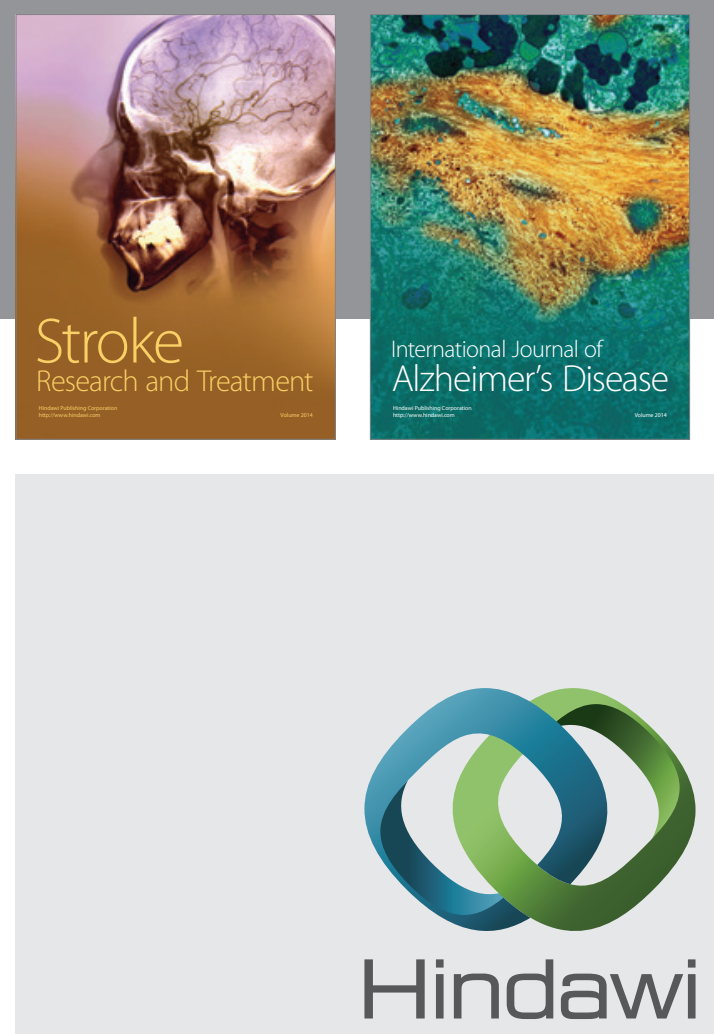

Submit your manuscripts at

http://www.hindawi.com
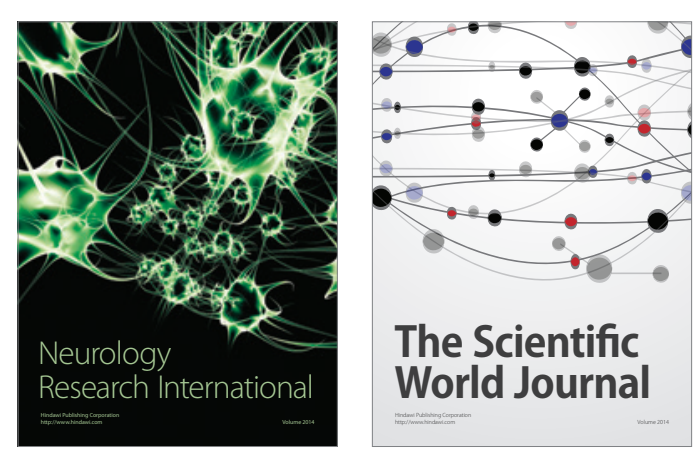

The Scientific World Journal

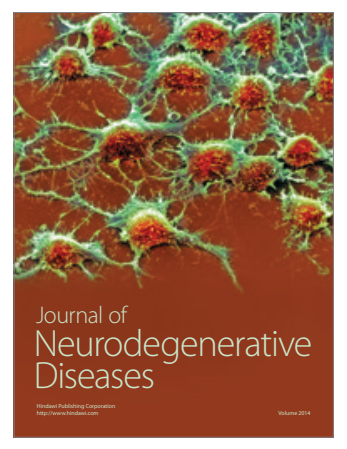

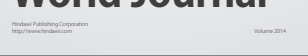

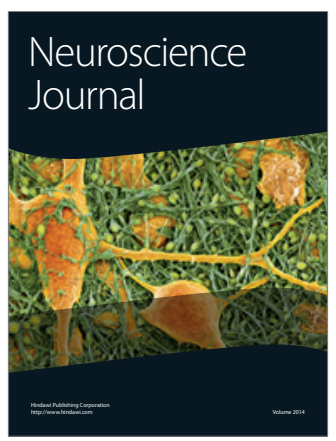

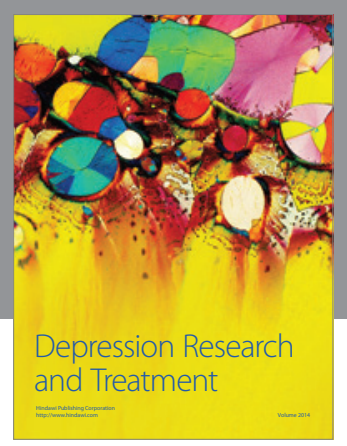
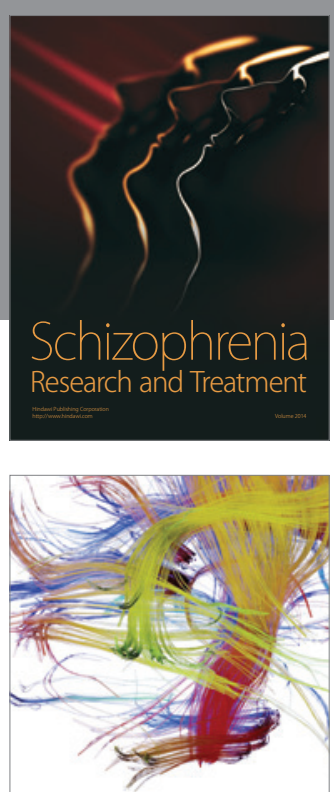

Brain Science

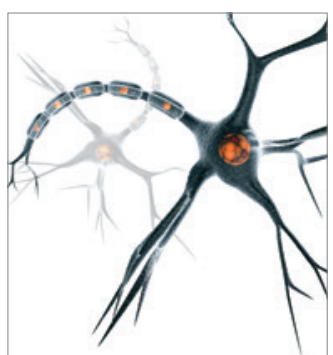

Neural Plasticity
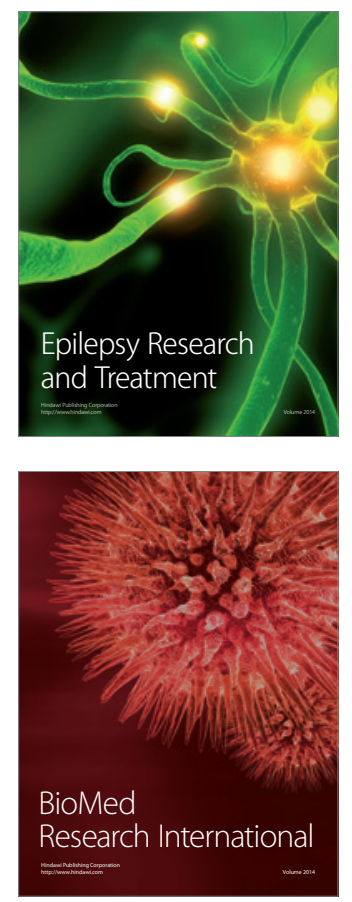

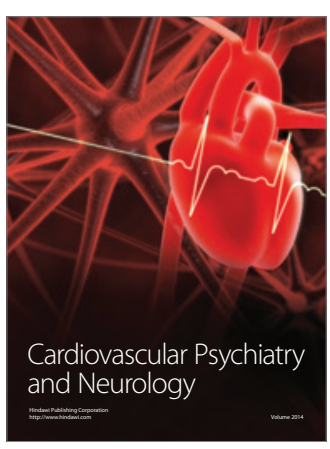

Parkinson's

Disease
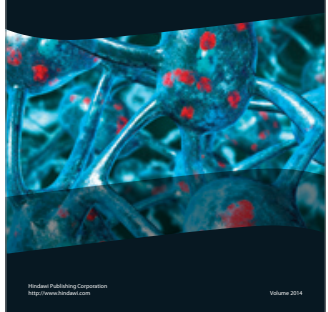